\title{
Factors Limiting and Affecting the Use of Market Information Systems in Sahelian Countries
}

\author{
Ouédraogo Ferdinand \\ University of Ouaga II, Ouagadougou, Burkina Faso \\ Email: ouedraogo.ferdinand@yahoo.fr
}

How to cite this paper: Ferdinand, O. (2019) Factors Limiting and Affecting the Use of Market Information Systems in Sahelian Countries. Theoretical Economics Letters, 9, 2456-2476. https://doi.org/10.4236/tel.2019.97156

Received: July 30, 2019

Accepted: September 27, 2019

Published: September 30, 2019

Copyright (อ 2019 by author(s) and Scientific Research Publishing Inc. This work is licensed under the Creative Commons Attribution International License (CC BY 4.0).

http://creativecommons.org/licenses/by/4.0/

\section{c) (i) Open Access}

\begin{abstract}
The objective of this study is to analyze the contributions of Market Information Systems (MIS) to the performance of agricultural markets in Sahelian countries, to identify and analyze the factors that limit and affect the use of these MIS for better efficiency of agricultural products markets. Indeed, the study showed that MIS can contribute to the better market performance of agricultural markets. According to the results obtained from the statistical and econometric analysis of the databases, the factors affecting the use of these MIS are: the age of the household head, his level of education, prices and the level of supply of products in the markets. The use of MIS has a positive effect on farmers' prices and possibly on their incomes. However, there are obstacles that limit their use by market actors: the low level of literacy and organization of the actors, the difficulties of the market actors to be able to use SMS and the Internet, the low level of dissemination of information to users. And the study showed that the age, the level of education, and the level of product offerings on the markets have a negative effect on their use.
\end{abstract}

\section{Keywords}

Information Market, Use of Market Information Systems, Performance of Markets, Improved Prices of Farmers and Their Incomes

\section{Introduction}

Agriculture is the main activity of people living in sub-Saharan Africa, and in the Sahel countries it is the main source of employment because of occupying more than $80 \%$ of households, the main source of wealth because of contributing to about $40 \%$ of Gross Domestic Product and more than 50\% of foreign exchange earnings of the different countries. 
Agricultural marketing is the activity that organizes the meeting between supply and demand of agricultural products to agree on a single price that is satisfactory to sellers and buyers. This unique price being the equilibrium price, is nothing else in reality than the amount of gross income obtained per unit of production sold.

Marketing is said to be effective when we can obtain the maximum of services (exchanges, transport, storage, packaging, etc.) with a minimum of costs and when we cannot increase the satisfaction of a player in this activity without lowering another.

In Sahelian Africa, food shortages in the cities and the countryside while there are surplus areas, the poverty of agricultural households while they accumulate surpluses of production, the inaccessibility to the products sold on the markets whereas the consumers have sufficient means to pay, are evidence that the functioning of agricultural markets is failing.

Despite the global food and financial crises of 2008, agricultural trade more than tripled in value from US $\$ 570$ billion in 2000 to US $\$ 1.6$ trillion in 2016 , with an annual growth rate of more than 6\% [1]. However, the number of hungry people in the world is still very high, estimated at around 793 million in 2014 [2]. In sub-Saharan Africa, the number of undernourished people increased from 176 million to 218 million between 1990 and 2014 according to the same source. These sufferings of the people illustrate and characterize some of the defects in the functioning of African economies, in particularly agricultural markets. In fact, the poor functioning of agricultural markets is generally characterized by the rigidity of demand, the seasonality and irregularity of agricultural production, price instability, market segmentation, and high transaction costs and the lack of transparency in the markets.

Harvests at the field level are sold at wholesale prices by producers in primary markets called collection markets. They can be distributed to local consumers in these markets by retail traders and/or resold by intermediate traders to wholesalers and semi-wholesalers who group them in secondary markets called bundling markets. In these regrouping markets, grouped harvests can also be distributed on the spot to consumers in the area by retailers who are retailers and/or resold by wholesalers and semi-wholesalers on terminal markets, particularly urban and frontier markets. Contrary to the theory of the pure and perfect competition market which assumes a homogeneity of the goods so that the functioning of the market is optimal, in Africa most of the agricultural products traded on the markets are of quality and heterogeneous calibrations. This forces a strong segmentation of these markets. Thus, each segment of the market corresponds to demand and specific consumption habits. It is very common to find that markets produce agricultural products of different qualities. Example: first-choice livestock entirely for export, second-rate livestock for slaughter for local consumption. In general, agricultural prices depend on supply and demand conditions, and supply in turn depends on local production, production in neighboring countries, and world output for agricultural goods export. However, in Africa, 
because of the failures or lack of certain markets, especially those of capital for the financing of farmers, the supply may also depend on farmers' cash needs in the sense that the more they need cash at harvest time to solve their social or economic problems (health, education, marriage, debt repayment, etc.) the more they will be forced to sell off their crops at very low prices. On the other hand, by deciding to store their harvests to wait for more favorable sales periods, farmers run the risk of not finding buyers for their products, since the demand is determined by the end-users, especially consumers, if the latter are poor (low purchasing power) and the State lacks the means to subsidize, rising prices can slow down demand and distort the market, especially price instability. The unfortunate consequences of this price instability are that, in a situation of vulnerability, agricultural households who for the most part sell most of their crops to pay off their debts or solve some very delicate social problems risk buying them back at double or triple prices. of the lean period. The remoteness of production areas, poor roads, inadequate or lack of transport, storage and packaging infrastructure may be a handicap for the smooth functioning of markets. In fact, if the infrastructure is poor, insufficient or absent, the intermediate, wholesaler and semi-wholesaler traders will tend to make farmers and consumers bear the costs of transactions related to the transport of goods, storage, processing and packaging of agricultural products that they have acquired and wish to resell. They will now be influencing farmers to lower prices and consumers to get high prices by justifying the transaction costs they endorse.

The supply of agricultural goods is not always flexible to price changes. Indeed, despite better buying prices offered by buyers in the markets, the isolation of the zones, the lack of transport, credit and price information services and the precise location of buyers may limit the transfer of products from the production areas to the places of demand for these products. So an increase in producer prices may not lead to an increase in supply. Demand for farm goods may not increase following lower prices. In theory, we know that households increase their consumption as a result of an increase in their incomes and reduce their consumption when income drops. The price as a signal of business opportunities is not always obvious in the case of agricultural markets. As a result, the level of poverty among households is characterized by a fall in income and their purchasing power, making them relatively insensitive to lower prices for agricultural products. Also, importing agricultural products that are perfectly substitutable for local products can limit the demand for local products. In Africa, agricultural goods are not produced continuously throughout the year, except for off-season crops through irrigation activities, which are generally small-scale activities at the moment. Yet the demand for agricultural products is fairly constant over time. Because agricultural production is mainly dependent on rainfall in Africa (good rainfall indicating good harvests, poor rainfall, poor harvests), and other climatic hazards such as floods and pockets of drought and attacks of insect pests of crops, it is difficult to record regular agricultural production. The quan- 
tity and the quality of the agricultural productions are thus very variable and very irregular from one year to another especially that the conditions of production are little controlled.

However, authors of economic theories such as Akerlof [3], Spence [4], Coase [5] and North [6] have demonstrated that market failures are related to imperfect information problems between actors, particularly asymmetries of information, negative externalities, the existence of market power and high transaction costs. And since the work of the neo-classics, it is accepted that the pure and perfect competition market can only be effective if all the actors have access to the perfect, complete and free information on all the economic transactions that take place in the markets, in particular, information on the quality, quantities and prices of goods and services exchanged.

Market Information Systems (MIS) are devices that have been proposed to reduce market information asymmetries in order to be able to obtain transparent and efficient markets, to also regulate these markets and to reduce transaction costs [7] [8].

Unfortunately their usefulness and effectiveness are more and more questioned because the results they could reach for their majority are far from satisfactory. They are charged to be unable to generate and disseminate reliable, profitable and marketable information, to be inaccessible to the actors for whom they are primarily intended, to be instruments of lesser utility and less recourse for decision-makers with regard to catches; decisions; unable to provide self-regulation of the markets, to be unable to disseminate information that is adapted to the real needs of the actors and finally to be unable to continue after the end of the projects without the financing of the donor funds [9].

MIS have been defined in the 1980s by FAO as a service, usually public, which periodically collects in wholesale and retail markets, in rural groupage markets, all the necessary information about prices, and quantities of agricultural commodities in order to make them available for farmers, traders, consumers, administrators through the media.

MIS development and expansion in the world and in Africa in particular, have evolved into two phases: a first phase marked by manual and semi-automated collection and dissemination of information (collection by individuals and broadcast by radios and newsletters) or first-generation MIS (MIS1G), and a second phase marked by intensive use of mobile telephony and the internet for the collection and dissemination or second-generation MIS (MIS2G).

The objective of this study is to analyze the contributions of MIS to the performance of agricultural markets in Sahelian countries, to identify and analyze the factors that limit and affect the use of these MIS for more efficient markets.

This paper is structured in 4 sections: a first section entitled "Theoretical and Empirical Debates on the Contribution of MIS to Market Performance" discusses theoretical and empirical debates on the contribution of information and 
MIS to market performance and efficiency, a second section, "Choice of Analytical Model, Sources of Data Collected, Sampling, Processing and Analysis", justifies the choice of model, data sources and sampling for the analysis of factors limiting and affecting the use of MIS in Sahelian Africa, a third section entitled "Results" presents firstly descriptive statistics on obstacles to the use of MIS in Sahelian countries and secondly factors affecting the use of MIS in Sahelian countries. The last section was dedicated to the discussion of the results.

\section{Theoretical and Empirical Debates on the Contribution of MIS to Market Performance}

\subsection{The Contribution of Perfect Information to Market Efficiency}

Information has been defined as knowledge of the facts or behaviors of others, past, present or projected [10].

However, it is only very recently that information has been considered as an economic good with its own value allowing individual and collective decisions.

The pure and perfect competition market is considered the only economically and socially efficient market because it allows a better allocation of resources.

According to the neo-classics, this market can only be effective under the following conditions: 1) the atomicity of supply and demand: Sellers as well as buyers must be in high numbers on the market. This has the effect of making impossible the influences of each on the prices at which goods and services are exchanged, 2) the free entry and the free exit of the sellers and the buyers on the market when they want it: It does not exist possible barriers to buyers and sellers at market entry. Everyone can enter freely for his transactions and come out freely. This can lead to an increase in the number of operators in the market (buyers and sellers), especially through the entry of new competitors, and 3) homogeneity of products sold on the market: goods traded on the market must be homogeneous. Due to the perfect substitutability of goods all exchanges on the market must be realized at the same price, 4) market transparency: all economic agents must have perfect, complete and free information on all economic transactions on the markets, including information on the quality, quantities and prices of goods and services traded. Market failures are most often the result of a breach of one of these four conditions of pure and perfect competition and the imperfection of information, a breach of the fourth condition of the pure and perfect competition market not allowing it not to be economical and socially effective.

The work of Hayeck F, Hirwickz L, Stiglitz J and Grosmman S has shown that market performance depends on their ability to ensure the dissemination of perfect information between economic agents. A high degree of imperfection of the information circulating between the agents could lead, according to them, to a suboptimal allocation of resources, an elimination of competition and competitiveness and therefore to a market failure.

For authors such as Porter [11] and Caves [12], the information market and 
the product market are closely linked. Thus in each product market coexists a market of information on the qualities of the products offered.

The authors of a neokeynesian theory [13], like those of the neoclassical theory, unanimously agree that the information which is at the basis of a functioning of the pure and perfect competition market is public information that in addition to being perfect and complete, it must be available and free for all actors, so a collective good, indivisible and inappropriate.

When information is produced, no agent can prevent another from using it because it is potentially available to all. It is these two characteristics of information (indivisibility and inappropriateness) which, according to the neokeynésiens, are at the origin of the externalities that it generates namely direct economic relations between agents not giving rise to an exchange through the mechanisms of the market, thus creating market failures.

Neokeynesians also attribute other characteristics that are intrinsic to the information itself. These characteristics include the value and uncertain quality of information and its asymmetry: authors such as Arrow [13] argue that the value of information is known to the buyer only when acquired by Shapiro and Varian [14] further confirm this theory before that the quality of the information is uncertain and is revealed only in use. High product prices signal high product quality, and low prices signal poor product quality, and cheaper, lower-priced products will invade the market and drive out products deemed too high for quality [3]; In addition to uncertainties about its value and quality, it should be added low-cost reproducibility. The copy of the CD-ROM of an encyclopedia costs practically nothing compared to the production of the first copy [15]. The production of information is expensive but its reproduction is inexpensive.

\subsection{The Contribution of MIS to Market Performance}

Authors such as Bowbrick [16] questioned the usefulness of first-generation MIS by demonstrating in a study the ineffectiveness of horticultural public MIS by the fact that the information they disseminate is not used by the targets groups because it is biased by errors in the collection and/or presentation. A CTA study [17] on first-generation MIS from Botswana, Ethiopia, Ghana and Zimbabwe showed that these MIS did not achieve the expected results. Indeed, the delays in the dissemination of information, the non-interactive mode of diffusion could not allow to take into account the needs of the actors [18].

Using Houck's [19] model for three market pairs for the period 1995-2006, Mugoya et al. [20] in their study of maize markets in Uganda found that MIS had a positive influence on the performance of these markets, allowing merchants to increase their profits.

Svensson and Yanagizawa [21], studying the impact of a Ugandan SIM, called Foodnet, broadcasting via a radio program information on farm gate prices paid to corn farmers showed that these maize producers have increased the share of production sold by $32 \%$ for all crops combined. 
These authors attribute these impacts to an improvement in the bargaining power of producers over buyers.

Recent studies have assessed the impact of second generation MIS on farmers' behaviors and incomes.

Indeed, in countries such as India and Bosnia and Herzegovina, Goyal [22], Arapovic and Karkin [23] have shown that second-generation MIS have contributed to improving the efficiency of consumer markets. Jensen [24] and Aker [25] showed that the mobile phone has positive effects on food trade in South Africa and Niger.

Goyal [26] has successfully assessed the impact of the introduction of Internet kiosks in soybean-producing villages in India, finding that this initiative has significantly improved the trading capacity and market power of small farmers againt wholesalers.

Subervie and Galtier [27] as well as Courtois and Subervie [28] carried out an initial analysis of the ESOKO MIS impact in sub-Saharan Africa and found that this MIS improved prices for maize and peanut producers respectively of the order of $10 \%$ and $7 \%$.

On the other hand, Fafchamps and Minten [29], studying MIS Reuters Market Light (RML) in India, came to the conclusion that there was no significant impact of this MIS on the behavior of the producers in their sample.

\section{Choice of Analysis Model, Sources of Data Collected, Sampling, Processing and Analysis}

\subsection{Choice of the Analysis Model of Factors Affecting the Use of SIMs}

One of the aims of this study is to highlight the factors affecting the use of MIS in the Sahel countries. The analysis is done using a probit model to identify variables that have significant effects on the probability of using agricultural MIS in Sahelian countries $\left(y_{i}\right)$. Indeed, the dependent variable is a binary variable that takes the value 0 if the farmer does not use the MIS and the value 1 if he uses the information disseminated by the MIS in his decisions. The use of linear models is therefore not suitable because of the small variance of the dependent variable. Discrete choice models are appropriate [30]. What is modeled here is not the dependent variable but the probability that it takes the value 1 . In these cases the logit and/or probit models are appropriate. Both models are symmetrical about the point $(0 ; 1 / 2)$.

To model this probability, suppose that there is a latent variable $y_{i}$ such as:

$$
y_{i}= \begin{cases}1 & \text { si } y_{i}^{*} \geq 0 \\ 0 & \text { si } y_{i}^{*} \prec 0\end{cases}
$$

In addition, suppose that depends on a certain number of explanatory variables grouped in a vector $X$. We thus have:

$$
y_{i}^{*}=\beta^{\prime} X_{i}+\varepsilon_{i}
$$


with $\beta^{\prime}$ a parameter vector and $\varepsilon_{i}$ the error term that follows a centered-reduced normal distribution. As $y_{i}^{*}$ is an unobserved latent variable, the probability of $y_{i}$ taking the value 1 can be defined as follows:

$$
\begin{aligned}
\operatorname{Prob}\left(y_{i}=1\right) & =\operatorname{Prob}\left(y_{i}^{*} \geq 0\right) \\
& =\operatorname{Prob}\left(\beta^{\prime} X \geq-\varepsilon\right)
\end{aligned}
$$

The probability that a farmer uses the information disseminated by the MIS $\left(P_{i}\right)$ is affected by the $X$ factors; so we have:

$$
\operatorname{Prob}(y=1)=\varphi\left(\beta^{\prime} X_{i}\right)
$$

with $\varphi$ the distribution function of the normal centered-reduced law. By exploding $X$ into its components, we obtain the empirical model. The estimation of this model makes it possible to identify the factors that have significant effects on the probability of using the information disseminated by the agricultural MIS in the Sahel countries.

\subsection{Sources of Collected Data, Sampling, Processing and Analysis}

It is the CILSS databases that has been used for statistical analyses and maximum likelihood estimates. It is a database from seven Sahelian countries in sub-Saharan Africa, namely Burkina, Mali, Niger, Senegal, Mauritania, Gambia and Chad.

These databases were generated in 2017 following a CILSS survey of 25 Agricultural Market Information Systems institutions in these 7 Sahelian countries and 250 market information users who consist exclusively of farm households (farmers and pastoralists).

To carry out field surveys, CILSS with the financial support of the Africa Development Bank (AfDB), the technical support of the African Institute of Rural Bio-economics (IABER), used two types of data collection tools: an interview guide that collected data from resource persons in 25 MIS institutions spread across the 7 Sahelian countries for the analysis of the supply of market information; and a questionnaire that was administered to 250 farm households using market information for analysis of the demand for information in the 7 countries studied. The 250 farm households surveyed are made up of men for the majority, $82 \%$. This is understandable since the surveys have mainly affected heads of households and in the Sahel the heads of agricultural households are for the most part men who claim to be the best able to always answer questions of common interest.

These farming households all belong to agricultural professional organizations considered representative in the 7 countries. Data from 250 farm households representing potential MIS users, mostly small and large grain and livestock producers, were examined.

However, data that was valid for econometric analysis accounted for $70 \%$ of the sample surveyed. SPSS 20 and Stata 13 software were used for data processing and analysis. 
Crossing the information obtained from the desk study with that obtained from the interviews and surveys with the MIS institutions and the agricultural households allowed a consolidation of the results presented in this paper.

\section{Results}

\subsection{Descriptive Statistics on Obstacles to the Use of MIS in Sahelian Countries}

Our study shows relatively high rates of illiteracy among the economic actors we met on the markets of Sahelian countries (Table 1).

These results are relatively close to those of UNDP for the same countries in 2011.

Thus, being mostly illiterate, it is obvious that farm households do not know how to use SMS and the internet as written means of communication to access market information or to communicate it to their partners.

The level of organization of market actors is not yet perfect in some countries (Table 2).

It is accepted that professional organizations are channels for the circulation of information between members.

Belonging to a professional organization allows agricultural households to access market information and at a lower cost than a personal commitment.

However, the level of organization of market players in Sahelian countries is not totally perfect and still needs to be improved.

Table 3 indicates that in some countries, such as Mauritania, Senegal, Chad and The Gambia, the proportion of market players who are not members of any professional organization is still important and the attendance of members at the monthly and quarterly information meetings convened by the general assembly of farmers' organizations remains very weak.

The study showed that most of agricultural market actors are unable to use internet and SMS: $71 \%$ of market actors still did not use the internet, and $45 \%$ of these market actors still did not know how to use SMS.

If factors such as illiteracy, and lack of organization can be obstacles to the use

Table 1. Illiteracy level of market actors in the seven Sahelian countries.

\begin{tabular}{cc}
\hline Countries & Level of illiteracy of the actors (\%) \\
\hline Niger & 57 \\
Mali & 75 \\
Burkina & 96 \\
Sénégal & 95 \\
Mauritanie & 90 \\
Tchad & 89 \\
Gambie & 94 \\
\hline
\end{tabular}

Source: obtained from CILSS and AfDB database analysis through 2017 SIM2G survey. 
Table 2. Level of membership of market actors to a professional organization and attendance of organiszation members at the monthly and quarterly information meetings.

\begin{tabular}{ccc}
\hline Countries & $\begin{array}{c}\text { Level of membership in a farmers } \\
\text { organization } \\
(\%)\end{array}$ & $\begin{array}{c}\text { Attendance at the monthly and } \\
\text { quarterly information meetings } \\
(\%)\end{array}$ \\
\hline Sénégal & 64 & 20 \\
Gambia & 77 & 10 \\
Mali & 97 & 15 \\
Burkina Faso & 85 & 17 \\
Niger & 100 & 25 \\
Tchad & 75 & 22 \\
Mauritania & 31 & 12 \\
\hline
\end{tabular}

Source: obtained from CILSS and AfDB database analysis through 2017 SIM2G survey.

Table 3. Level of use of the Internet and SMS by agricultural market actors in Sahelian countries.

\begin{tabular}{ccc}
\hline Countries & $\begin{array}{c}\text { Proportion of market actors } \\
\text { unable to use Internet } \\
(\%)\end{array}$ & $\begin{array}{c}\text { Proportion of market } \\
\text { actorsunable to use SMS } \\
(\%)\end{array}$ \\
Sénégal & 67 & 45 \\
Gambie & 53 & 44 \\
Mali & 65 & 37 \\
Burkina Faso & 77 & 48 \\
Niger & 81 & 46 \\
Tchad & 83 & 45 \\
Mauritanie & 70 & 60 \\
All Sahelian countries studied & 71 & 45 \\
\hline
\end{tabular}

Source: obtained from CILSS and AfDB database analysis through 2017 SIM2G survey.

of MIS in Africa. What about the ignorance of farm households about the existence of MIS and how they work?

The study showed (see Table 4) that most MIS in Africa lack visibility. Indeed, it can be seen that most of the MIS existing in the Sahel are completely ignored by the actors to whom they were previously intended. The results of this study show that for all the agricultural households surveyed in the 7 Sahel countries, $44 \%$ are only informed of the existence of public MIS. And for private MIS $14 \%$ of these farming households are only informed.

In doing so, if the implemented MIS are not visible by the actors to whom they are previously intended, it is obvious that they cannot use them.

Yet second-generation MIS focus on these two tools for collecting and disseminating information.

Finally, the results of our study indicated that the share of the budget devoted 
Table 4. Farm households informed of the existence of public and private MIS.

\begin{tabular}{ccc}
\hline Countries & $\begin{array}{c}\text { Households informed of the } \\
\text { existence of public MIS. } \\
(\%)\end{array}$ & $\begin{array}{c}\text { Households informed of the } \\
\text { existence of private MIS. } \\
\text { (\%) }\end{array}$ \\
\hline Sénégal & 22 & 6 \\
Gambia & 20 & 24 \\
Mali & 51 & 29 \\
Burkina Faso & 46 & 3 \\
Niger & 84 & 7 \\
Tchad & 44 & 14 \\
Mauritania & 31 & 14 \\
All Sahelian countries studied & 45 & \\
\hline
\end{tabular}

Source: obtained from CILSS and AfDB database analysis through 2017 SIM2G survey.

to the dissemination of information is very low and almost non-existent in some countries.

About a total budget of 2,758,621 US dollars is allocated each year to the functioning of the agricultural and livestock public MIS of the seven countries studied (Table 5).

However, $50 \%$ of this budget is allocated to information production, and only $2 \%$ is devoted to activities of dissemination of informations. The rest of the budget, about $48 \%$ of it is wasted or diverted through activities of convenience such as training workshops, and supervisory missions mounted from scratch to trap funding from donors and that bring no added value in reality. The information collected, which is not actually disseminated by the MIS, could also explain the low level of ownership of these MIS.

\subsection{Factors Affecting the Use of MIS in Sahelian Countries}

Despite the obstacles that limit the use of MIS by lots of economic actors on the markets, we were able to identify the factors favoring the use of MIS in Sahelian countries. The results of probit model estimates by maximum likelihood have shown (see table below) that the age of the household head, his level of education, the prices and the level of supply of the products have significant effects on the probability of using MIS in the 7 Sahelian countries studied. On the other hand, the effects of variables of interest such as possession (owning) of a mobile phone, a radio set, belonging to a peasant organization and access to the Internet are not significant.

The results of the estimates are summarized in Table 6 . The first column of the table summarizes the results of the estimate and the second column summarizes the marginal effects and the semi-elasticities.

The table above shows that the factors that have significant effects on the probability of using MIS in the 7 Sahelian countries studied are: the age of the heads of agricultural households, their level of education, and finally the prices 
Table 5. Total budget allocated to agricultural and livestock public MIS and sharing.

\begin{tabular}{ccccc}
\hline Countries & $\begin{array}{c}\text { Total budget allocated } \\
\text { to agricultural and } \\
\text { livestock public MIS } \\
\text { (US Dollars) }\end{array}$ & $\begin{array}{c}\text { Share of total } \\
\text { budget for } \\
\text { production of } \\
\text { information } \\
\text { (\%) }\end{array}$ & $\begin{array}{c}\text { Share of total } \\
\text { budget for } \\
\text { dissemination of } \\
\text { information } \\
\text { (\%) }\end{array}$ & $\begin{array}{c}\text { Share of } \\
\text { total budget } \\
\text { wasted } \\
(\%)\end{array}$ \\
\hline Sénégal & 924,138 & 52 & 0 & 48 \\
Gambia & 60,345 & 100 & 0 & 0 \\
Mali & 732,759 & 45 & 1 & 54 \\
Burkina Faso & 227,586 & 20 & 20 & 60 \\
Niger & 353,448 & 59 & 2 & 39 \\
Tchad & 250,000 & 82 & 0 & 19 \\
Mauritania & 210,344 & 44 & 0 & 46 \\
All Sahelian & $\mathbf{2 , 7 5 8 , 6 2 1}$ & 52 & 2 & \\
countries studied & & & & \\
\hline
\end{tabular}

Source: obtained from CILSS and AfDB database analysis through 2017 SIM2G survey.

Table 6. Factors affecting the use of MIS in Sahelian countries.

\begin{tabular}{|c|c|c|c|c|}
\hline Probit & & & dprobit & \\
\hline SIM & Coef. & $P>Z$ & $\mathrm{dF} / \mathrm{dx}$ & $P>Z$ \\
\hline age & -0.022226 & 0.038 & -0.00847 & 0.038 \\
\hline Edu & -0.1610865 & 0.042 & -0.0613875 & 0.042 \\
\hline Tel & -0.8283453 & 0.255 & -0.2570733 & 0.255 \\
\hline $\mathrm{Lp}$ & 0.1627252 & 0.000 & 0.062012 & 0.000 \\
\hline Lof & -0.0881467 & 0.027 & -0.0335913 & 0.027 \\
\hline Op & 0.3508086 & 0.222 & 0.1365449 & 0.222 \\
\hline Web & 0.2788403 & 0.302 & 0.1036452 & 0.302 \\
\hline Radio & 0.1221759 & 0.742 & 0.0471666 & 0.742 \\
\hline _cons & 0.7945698 & 0.437 & & \\
\hline \multicolumn{3}{|c|}{ Number of obs $=167$} & \multicolumn{2}{|c|}{ Number of obs $=167$} \\
\hline \multicolumn{3}{|c|}{$\operatorname{LR} \operatorname{chi} 2(8)=31.78$} & \multicolumn{2}{|c|}{$\operatorname{LR} \operatorname{chi} 2(8)=31.78$} \\
\hline \multicolumn{3}{|c|}{ Prob $>$ chi $2=0.0001$} & \multicolumn{2}{|c|}{ Prob $>$ chi $2=0.0001$} \\
\hline
\end{tabular}

Source: obtained from CILSS and AfDB database analysis through 2017 MIS2Gsurvey.

and the level of supply of agricultural products on the markets. We note that the price coefficient is positive, while the coefficients associated with the age of the heads of agricultural households, their level of education, and the level of supply of agricultural products on the markets are negative. Which would mean that the age of the household heads, their level of education and the volume of agricultural supply has negative effects on the probability of using the MIS, proving that MIS are used by young people producers who would be better able to master the new information and communication technologies, which are the main means of disseminating MIS information. The negative sign of the coefficient 
associated with education is explained by the fact that the level of education negatively affects the probability of being in the primary sector. If the level of education is high, agricultural activity tends to become a secondary activity. The negative sign associated with the supply coefficient is explained by the fact that MIS are used by small producers (farmers). They generally have neither the market power nor the means to develop their own market information circuit. They use the information disseminated by MIS to optimize their business activities.

The positive sign associated with the price means that the price level increases with the use of MIS. The search for better prices therefore leads agricultural households to become interested in the information disseminated by the MIS

So we conclude that the results obtained from the estimation of these two models are globally significant.

\section{Discussions}

Our study has shown that MIS can contribute to a better performance of agricultural markets. According to the analysis of the databases of the 7 countries studied, the use of SIM remains low in the Sahelian countries and the factors affecting their use are: the age of the head of the household, his level of education, prices and the level of products on the markets. The use of MIS has a positive effect on farmers' prices and possibly on their incomes. However, obstacles that limit their use by market actors are: the low level of literacy and organization of the actors, the difficulties of the market players for the use of SMS and the Internet and finally the low level of diffusion of informations for users. The study also showed that age, education and the level of product offerings on the market have a negative effect on the use of MIS.

The search for better prices therefore leads agricultural households to take an interest in the information disseminated by MIS. The study showed that the price level increases by $6 \%$ with the probability of farmers using MIS. This result tends to be consistent with those found by Subervie and Galtier [27], Courtois and Subervie [28] who showed that the ESOKO MIS representing a second-generation MIS enabled producers to receive higher prices for maize around $10 \%$ and higher prices for peanuts reaching around 7\%. However, for reasons of methodology and limitations observed, authors such as Staatz et al. [31] have reservations about the generalization of the results obtained from these studies for all types of MIS.

The present study has shown that the actors in the market have free access to the information disseminated by the MIS. This gives us the proof that the information produced and distributed by these MIS is public and accessible by the majority of players in the markets. This collective ownership of information is that demanded by neokeynesians and neoclassicals for the efficiency of markets. Since it is difficult to exclude an agent from the consumption of an information asset considered as a collective good, individuals taken individually have no in- 
terest in announcing the true value of their consent to pay for this property, so as not to have to pay this good; since knowing all that when this good is produced, it is in principle available for free and in full for them or accessible at a price below its real value on the market. A study by Sakalaki and Thépaut [32] showed that individuals tend to underestimate the value of informational goods by about $30 \%$ compared to that of material goods.

The level of illiteracy is still very high in the Sahelian countries. However, according to Simon's [33] theory of limited rationality, the illiteracy of economic actors in the market is a factor that limits the rationality of the actors in their decision-making. When the information is disseminated by the MIS in writing including SMS, newsletters, emails or websites, illiterate actors can only use a small portion of the information disseminated.

In doing so, the low visibility of MIS by farming households in Africa may be partly justified by their low level of literacy and organization, thus limiting their ability to use written information channels to inform themselves: written media (newspapers, newsletters, journals etc.) SMS, e-mails, internet, posters and billboards etc.

African countries in the Sahelian zone allocate large amounts to produce information to meet the demand, unfortunately this production of information is not disclosed to the knowledge of the applicants and remains stuck in the drawers. Based on the fact that the information produced should correspond to the demand (information collected equals requested information), we can state clearly that the production of information corresponding to the demand is important but that the supply to satisfy the demand is insufficient. However, in addition to being insufficient, the information available to applicants does not appear to be of good quality in order to obtain genuine support from farmers and produce real impacts on their behavior. In general, economic actors in the markets find this information unreliable, obsolete and out of step with reality. The dissemination of collected information, the purpose of which is to make the supply of information available to the applicants, is an essential activity for the proper functioning of the markets, but nevertheless very neglected in the Sahelian countries.

Consequences: it leads to mismatches between the limited information offered by MIS and the demand for information from market actors, information shortages for these actors despite the abundance of information collected or produced. Robinson [18] pointed out that delays in the dissemination of information, the non-interactive mode of diffusion can not allow to take into account the real needs of the actors. And for Galtier and Egg [7], the mismatch between the information demand of the actors and the information offer of the MIS limits their effect on the performance of the markets. This inadequacy may force private operators to have their own sources of information [7].

Since information is an experiential good in light of Arrow [13] theory by Shapiro and Varian [14], its demand can be limited when there is more uncertainty about its value and quality. This could make the functioning of the mar- 
kets more imperfect. In fact, since the buyer does not know the real quality of the information until he has acquired it, it will be very difficult for him to make a correct estimate of the quality of the information and to propose a price. According to Akerlof's law, it will thus tend to offer a price lower than the value of the equilibrium price of the information on the market.

The analysis of the theory of Porter [11] and Caves [12] on the interweaving and linking of the information market to the product market has shown us that the performance of product markets depends on that of the markets of informational goods that are structurally failing markets because the information exchanged is a private good often requiring research costs that could slow down its demand.

As the market for a product is intimately linked to the quality of market information, a sale transaction for a quantity of this product systematically incorporates that of the sale of information quality and a purchase transaction for a quantity of this product, integrates that of the purchase of information quality. However, it is difficult to distinguish in the sale price or the purchase price of the product, the share of information from that of the quantity of the product purchased or sold on the market. In other words the sale of the quantity of a given product is also a sale of information about this product and the purchase of the quantity of a given product also corresponding to the purchase of information about this product.

These intrinsic characteristics of production and information management limit the development of an optimal Pareto information market. Information therefore has a systematically imperfect and failing market.

However, the optimal functioning of the product market requires a perfect functioning of the information market, in particular an operation capable of eliminating the asymmetries of information between the actors (anti-selection and moral hazard), eliminating transaction costs in particular those related to the search for information by the actors, to eliminate the externalities and possibly the stowaways that lead to free access and to over-exploitation, thus compromising the production and the demand for information.

Based on the principle of equality between supply and demand in the information market, we will have to admit that bad information exists in the market because there is a demand.

Indeed, even if the MIS disseminates perfect informations (informations of good quality) to farming households allowing them to distinguish between good and bad informations on the markets; there will always be a quantity and an irreducible quality of bad informations that will be accepted especially by the poorest farming households, so the demand for bad informations will never totally disappear in favor of right informations disseminated by MISs.

This marks a certain limit for MIS whose objective is to produce and disseminate the right information for agricultural households.

Debates on the consequences of collective or private ownership of information have not been definitively settled. Indeed, when we analyze the theory of Porter 
[11] and Caves [12] on the nesting or linking of the information market to the product market we can argue that the information exchanged on the product market is private information, so a private good having a value including a price that would certainly result from a confrontation between supply and demand. This private information as a private asset, could certainly be divisible and appropriable like any other normal good on the market.

Thus we should evolve in the definitions of the basic concepts of economic theory to take into account now the value and the nature of the information that is incorporated in the product. In doing so, the market value of a product for a producer should be a function of its cost of production and the costs associated with the economic interference of the markets that organize the crossover of supply and demand. However, it is the consumer who will settle the final level of this value from the satisfaction he will hope to withdraw in the consumption of this product. Thus, at the basic use value, the consumer should add other additional use values, especially those of beliefs about quality, availability, therapeutic virtues in the consumption of this good (cancer cure, regulation of blood pressure etc.) to be closer to its actual exchange value in the market.

When an economic agent suffering from arterial hypertension tests the consumption of three food products $X, Y$, and $Z$ sold respectively at prices $P_{X}, P_{Y}$, $P_{Z}$, including $P_{X}<P_{Y}<P_{Z}$. Under the assumption that the consumption of these three goods each provides a certain level of satisfaction $U_{X}, U_{Y}, U_{Z}$ which consists in calming the hunger and another level of satisfaction $U_{X}, U_{Y}, U_{Z} z$ which is to heal hypertension, we can admit that to quell hunger the consumption of goods $X, Y$, and $Z$ must achieve the objectives $U_{X}=U_{Y}=U Z$. However, to be cured of hypertension it is the consummation of $X$ or $Y$ or $Z$ that will allow the probable satisfaction $U_{X}$ or $U^{\prime} y$ or $U^{Z} z$.

The goal of consuming each of the food goods to calm hunger is a perfect information for the economic agent. On the other hand, to consume the good which will cure of hypertension remains an uncertain and imperfect information.

If the product $X$ of value $P_{X}$ is the one whose consumption could relieve the economic agent of his health problem, the latter will substitute the goods $Y$ and $Z$ with the good $X$ and can accept the substitution of the price $P_{X}$, by prices higher especially $P y$ or $P Z$ which will become the minimum market value of good $X$ (Table 7).

Table 7. Perfect information increasing and decreasing in the market.

\begin{tabular}{cccccc}
\hline $\mathrm{N}^{\circ}$ & Food stuff & $\begin{array}{c}\text { Use value 1: } \\
\text { calm hunger }\end{array}$ & $\begin{array}{c}\text { Use value 2: } \\
\text { Cure hypertension }\end{array}$ & $\begin{array}{c}\text { Predictable } \\
\text { market value }\end{array}$ & Real market value \\
\hline 1 & $X$ & $P 1 x$ & $P 2 x$ & $P 1 x+P 2 x$ & {$[P 1 y+P 2 x, P 1 z+P 2 x]$} \\
2 & $Y$ & $P 1 y$ with $P 1 y>P 1 x$ & $P 2 y=0$ & $P 1 y$ & $P 1 y$ \\
3 & $Z$ & $P 1 z$ with $P 1 z>P 1 y$ & $P 2 z=0$ & $P 1 z$ & $P 1 z$ \\
\hline
\end{tabular}

Source: obtained from our analysis. 
Perfect information about the quality and availability of a good can increase or decrease its market value. So if one discovers new (positive) qualities of the good commonly used its exchange value may increase. On the other hand, if we discover negative qualities previously unknown to consumers, this market value may decrease. As an example, information on the scarcity of an agricultural product may increase its market value, and information on its availability may decrease.

In general, the study also showed that when market players find that the information collected and disseminated is of poor quality (unreliable information, obsolete and out of sync with reality), it would be necessary to investigate the production of information in order to relativize. Indeed, at the level of the MIS institutions, the processing of raw market price information (collected) in average prices (broadcast on radio, television, in newsletters and on mobile phones of market players) can in itself be a cause of the non-use of this information by these actors who would not find them fair or reliable, if they do not recognize these average prices on the markets. Indeed, if after listening to the broadcast of the average price of a cereal on the market on the radio, or if after receiving this average price on his cell, a farmer who frequents this market is still not able to identify or recognize this price from a specific seller in the market, it would be difficult for him to trust such a price as information disseminated. This is far from being the case since most post-processing SIMs generally broadcast average prices that are not recognized anywhere in the sellers "or buyers" markets.

\section{Conclusions}

The objective of this study was to analyze the contributions of MIS to the performance of agricultural markets in Sahelian countries, to identify and analyze the factors that limit and affect the use of these MIS for better market efficiency.

Our study has shown that MIS can contribute to a better performance of agricultural markets. According to the analysis of the databases of the 7 countries studied, the use of SIM remains low in the Sahelian countries and the factors affecting their use are: the age of the head of the household, his level of education, prices and the level of products on the markets. The use of MIS has a positive effect on farmers' prices and possibly on their incomes. However, obstacles that limit their use by market actors are: the low level of literacy and organization of the actors, the difficulties of the market players for the use of SMS and the Internet and finally the low level of diffusion of informations for users. The study also showed that age, education and the level of product offerings on the market have a negative effect on the use of MIS.

The level of illiteracy is still very high in the Sahelian countries. When the information is disseminated by the MIS in writing including SMS, newsletters, emails or websites, illiterate actors can only use a small portion of the information disseminated. In doing so, the low visibility of MIS by farming households in Africa may be partly justified by their low level of literacy and organization, 
thus limiting their ability to use written information channels to inform themselves: written media (newspapers, newsletters, journals etc.), SMS, e-mails, internet, posters and billboards etc.

African countries in the Sahelian zone allocate large amounts to produce information to meet the demand; unfortunately this production of information is not disclosed to the knowledge of the applicants and remains stuck in the drawers.

The production of information corresponding to the demand is important but the supply to satisfy the demand is insufficient. The information available to applicants does not appear to be of good quality in order to obtain genuine support from farmers and produce real impacts on their behavior. Economic actors in the markets find this information unreliable, obsolete and out of step with reality.

The dissemination of collected information, the purpose of which is to make the supply of information available to the applicants, is an essential activity for the proper functioning of the markets, but nevertheless very neglected in the Sahelian countries.

Information has a systematically imperfect and failing market. Perfect information about the quality and availability of a good can increase or decrease its market value. So if one discovers new (positive) qualities of the good commonly used its exchange value may increase.

The information market is embedded in the product market. So that the functioning of the product market is optimal for the product market, the functioning of the information market must be perfect.

When MIS work properly, they can help improve the prices and incomes of market participants, improve their trading capacity and their market share. Obstacles to the use of MIS may limit their contribution to market efficiency. Among these obstacles, we should remember the low level of literacy and organization of market players, the difficulties of market players in being able to use SMS and the internet and to be able to pay for access to the information disseminated by certain MIS, particularly MIS2G, the low visibility and reliability of MIS on the terrain, the part of the budget devoted to very weak and almost non-existent information dissemination in some Sahelian countries.

As for the factors that affect use, the study identified the age of the household head, his level of education, prices and the level of supply of products in the markets. The study showed that the use of MIS has a positive effect on farmers' prices and possibly on their incomes. On the other hand, the age, the level of education, and the level of product offerings on the markets have a negative effect on the use of the MIS.

MIS have great potential to increase market transparency, to increase the marketers' ability to negotiate, and improve income levels; but provided that these MIS are devices adapted to the needs of users, that these MISs are visible to its first users, that they can produce and disseminate reliable information, that the production and dissemination of market information account of the degree 
of interdependence or economic interference of markets, and that their financing is sustainable.

Thus, the selection of the samples of the markets to be covered by the MIS should now take into account the principle of economic interference of the markets, their functional interdependence for a large spread of information disseminated on the markets, to be able to achieve economies of scale when markets are perfectly integrated, to avoid waste of resources when markets are not or poorly integrated. In doing so, sampling MIS markets by assessing their interferences and their transactional weight with an economic interferences table would make a big contribution to MIS efficiency.

This dynamic lays the groundwork for the move towards smart MIS or third-generation MIS, signaling the end of organic MIS and physical markets.

\section{Conflicts of Interest}

The author declares no conflicts of interest regarding the publication of this paper.

\section{References}

[1] FAO (2018) The Global Report on Food Crises. Food Security Information Network.

[2] FAO (2015) Vue d'ensemble régionale de l'insécurité alimentaire en Afrique: Des perspectives plus favorables que jamais. Accra, FAO.

[3] Akerlof, G. (1970) The Market for "Lemons: Quality Incertainty and the Market Mechanism. The Quarterly Journal of Economics, 84, 488-500. https://doi.org/10.2307/1879431

[4] Spence, A.M. (1974) Market Signalling: Informational Transfer in Hiring and Related Screening Processes. Harvard University Press, Cambridge, MA.

[5] Coase, R. (1960) The Problem of Social Cost. Journal of law and Economics, 3, 1-44. https://doi.org/10.1086/466560

[6] North, D. (1992) Transaction Costs, Institutions, and Economic Performance. ICS Press, San Francisco, CA, 5.

[7] Galtier, F. and Egg, G. (2003) Le "paradoxe" des systèmes d'information de marché (SIM): Une clé de lecture issue de l'économie institutionnelle et de la théorie de la communication. Economieset Sociétés, 7-8, 1227-1260.

[8] David-Benz, H., Egg, J., Galtier, F., Rakotoson, J., Shen, Y. and Kizoto, A. (2012) Les SIM agricoles en Afrique subsaharienne. De lapremière àla deuxième génération. CIRAD, INRA, AFD, CTA, 89 p.

[9] Shepherd, A.W. (1998) Les services d'information sur les marchés: Théorie et pratique. FAO.

[10] Cotta, A. (1968) Dictionnaire de science économique, Edition Maison MAME.

[11] Porter, M. (1976) Interbrand Choice, Strategy, and Bilateral Market Power. Harvard University Press, Cambridge, MA.

[12] Caves, R.E. and Porter, M.E. (1977) From Entry Barriers to Mobility Barriers: Conjectural Decisions and Contrived Deterrence to New Competition. The Quarterly Journal of Economics, 91, 241-261. https://doi.org/10.2307/1885416 
[13] Arrow, K. (1962) The Economic Implication of Learning by Doing. Review of Economic Studies, 29, 155-173. https://doi.org/10.2307/2295952

[14] Shapiro, C. and Varian, H.R. (1998) Information Rules: A Strategic Guide to the Network Economy. The Journal of Technology Transfer, 25, 250-252.

[15] Thépaut, Y. (2002) Pouvoir, information, économie. Economica, Paris, 375.

[16] Bowbrick, P. (1988) Are Price Reporting Systems of Any Use? British Food Journal, 90, 65-69. https://doi.org/10.1108/eb011811

[17] CTA (2000) Review of Market Information System in Botswana, Ethiopia, Ghana and Zimbabwe. Study Report, 78.

[18] Robinson, V. (1998) The Importance of Information in the Resettlement of Refugees in the UK. Journal of Refugee Studies, 11, 146-160.

https://doi.org/10.1093/jrs/11.2.146

[19] Houck, J.P. (1977) An Approach to Specifying and Estimating Nonreversible Functions. American Journal of Agricultural Economics, 59, 570-5721. https://doi.org/10.2307/1239663

[20] Mugoya, M., Christy, R. and Mabaya, E. (2007) The Impact of the Market Information. Service on Pricing Efficiency and Maize Price Transmission in Uganda Working Paper, Department of Applied Economics and Management Cornell University, Ithaca, New York, 14853-17801.

[21] Svensson, J. and Yanagizawa, D. (2009) Getting Prices Right: The Impact of the Market Information Service in Uganda. Journal of the European Economic Association, 7, 435-445. https://doi.org/10.1162/JEEA.2009.7.2-3.435

[22] Goyal, A. (2008) Strategic Information Management under Leakage in a Supply Chain University of Maryland Joint Work with: Krishnan S. University of Pennsylvania, Pennsylvania, Philadelphia, PA.

[23] Arapovic Adisa, O. and Karkin, Z. (2015) The Impact of Agricultural Market Information System in Bosnia \& Herzegovina on Market Integration: Asymmetric Information and Market Performance. Khazar Journal of Humanities and Social Sciences, 18, 56-67.

[24] Jensen, R.T. (2007) The Digital Provide: Information (Technology), Market Performance and Welfare in the South Indian Fisheries Sector. Quarterly Journal of Economics, 122, 879-924. https://doi.org/10.1162/qjec.122.3.879

[25] Aker, J.C. (2008) Does Digital Divide or Provide? The Impact of Mobile Phones on Grain Markets in Niger. BREAD Working Paper 177.

https://doi.org/10.2139/ssrn.1093374

[26] Goyal, A. (2010) Information, Direct Access to Farmers, and Rural Market Performance in Central India. American Economic Journal: Applied Economics, 23, 22-45. https://doi.org/10.1596/1813-9450-5315

[27] Subervie, J. and Galtier, F. (2012) Systèmesd' Informationde 2ème Génération en Afrique Sub-saharienne: Etudesd' impacts. CIRAD, INRA, AFD, CTA, 76 p.

[28] Courtois, P. and Subervie, J. (2014) Farmer Bargaining Power and Market Information Services. American Journal of Agricultural Economics, 97, 953-977. https://doi.org/10.1093/ajae/aau051

[29] Fafchamps, M. and Minten, B. (2012) Impact of SMS-Based Agricultural Information on Indian Farmers. The World Bank Economic Review, 26, 383-414. https://doi.org/10.1093/wber/lhr056

[30] Greene, W. (2012) Econometric Analysis. 7th Edition, Prentice Hall, Upper Saddle River, NJ. 
[31] Staatz, J., Kizito, A., Weber, M. and Dembele, N. (2012) Challenges in Measuring the Impact of Market Information Systems. Cahiers Agricultures, Forthcoming.

[32] Sakalaki, M. (2007) How Much Is Information Worth? Willingness to Pay for Expert and Non-Expert Informational Goods Compared to Material Goods in Lay Economic Thinking. Journal of Information Science, 33, 315-325.

https://doi.org/10.1177/0165551506070709

[33] Simon, H. (1962) The Architecture of Complexity. Proceedings of the American Philosophical Society, 106, 467-482. 